\title{
CanIS Android Mobile Application For College
}

\section{Notice Board}

\author{
Disha M Kamath ${ }^{1}$, Shrehith K Kotian ${ }^{2}$ \\ Dept of Information Science and Engineering, Canara Engineering College, Mangalore ${ }^{1,2}$
}

\begin{abstract}
Many state-of-the-art and cutting-edge universities in the world rely on wooden notice board hanging on the wall to display announcements. We consider the case study of professional Colleges, where information is a vital key for knowing the updates of the campus.
\end{abstract}

\section{INTRODUCTION}

Android is a software stack for mobile devices that includes an operating system, middleware and key applications. It is an operating system for mobile devices such as smart phones and tablet computers. It is developed by the Open Handset Alliance led by Google. It's is built on a Linux foundation. Google purchased the initial developer of the software, Android Inc., in 2005. It allows developers to write managed code in a Java-like language that utilizes Google-developed Java libraries, but does not support programs developed in native code.

\section{OVERVIEW}

In this we are proposing work which will be beneficial to the students and reduces the manual work. The notices on the departmental level and department level, events, faculties and their profiles, college map with icons, alumni, photo gallery, placements and training all these modules will keep the students up to date. In the existing system, the majority of colleges maintain their records, notices, and other information in the manual process. Also students has to go particular faculty every time for negligible work. Sometimes the information collected by the students are not even sufficient and also incorrect sometimes, which leads to face the problems.

This app has 8 modules

Placements: These consists of campus recruitment notices such as information about recruiting company, campus interview date and other placement activities.

Photo gallery : This contains photos of events took place in department as well as college.

Alumni : This contains information about the alumni's of our department

Notification : This module contains general notices of our department and college

Campus Map : This module facilitated student to view location of different department and other area of the college and shortest way to rich there.

Faculty Profile : This module will help the students to view the information about the faculties of their college. For example Principal, HOD, teaching and non-teaching staff of college.

Student Login $\quad$ : This module maintains student profile and their personal database which would be protected.

Student can access their personal account whose access will be restricted to others. The personal account will contain information like biodata, academic details etc. This module can be beneficial for the final year students, student can get the information about training and placement.

Student will come to know about the companies who will visit in coming days and if the student is eligible then this module will send message to the eligible student. If the student wants to give any suggestion he/she can write their suggestions.

Parents

:Parents will get the details of student via SMS. Details like attendance and internal marks will be sent after every sessionals.

\section{PROBLEM STATEMENTS}

This project aims to build an android application for our college departmental notice board which notifies every instructions and updates of department. Update includes information about lecturers, upcoming departmental activities , upcoming holidays, placements, etc. It is easy to use and free of cost. 
The product functions are as follows:

\section{PRODUCT FUNCTION}

- The user must first download the app.

- After the app has been successfully downloaded the user must be able to enter its details by clicking the settings option. The settings option must contain name, contact number of the recipient based on the user.

- After gathering and storing all the details the app must work efficiently. It should appear as a widget on the screen.

- The app will have a good user interface so that the user can interact efficiently.

- The app will also have buttons which will provide features like Notification, map, students, faculty, parents, alumni, placement etc

\section{USER CHARACTERISTICS}

The user should know to operate an android smart phone.

- The basic knowledge of operating any android app is more than sufficient for a user to operate this app.

- Users are not expected to have a very high level of technical expertise.

This app is constrained to English language only.

- Once the user has installed the app and entered the required data it will be useful only for that particular user.

- The mobile phone must be connected to the service provider. For utilizing all features of this app, internet connection is essential.

\section{ARCHITECTURAL DESIGN}

Architecture has emerged as a crucial part of design process. The architectural design of a system is abstract, distilling away details of implementation, algorithm and data representation and concentrating on behavior and interaction of "black box" elements. Software architecture is developed as the first step toward designing a system that has collection of desired properties.

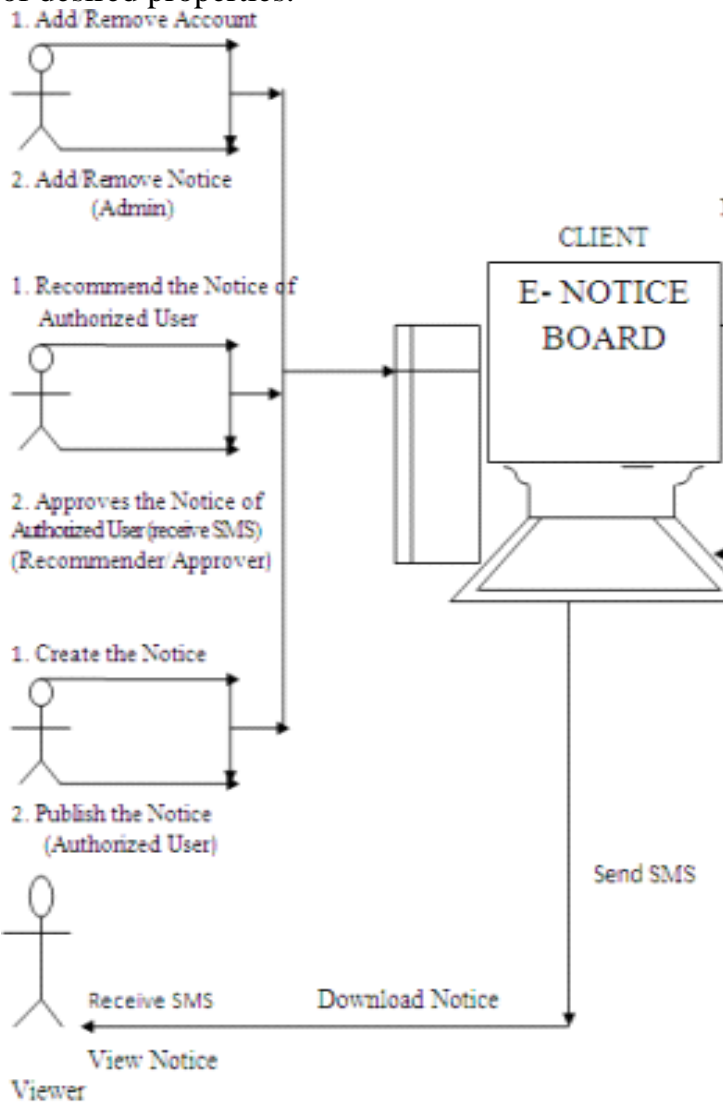

Figure: Architectural Design of CanIs App

The architecture consists of three "black boxes", the first one representing an Android based mobile or tablet platform, where this application can be installed. The Application requires connectivity with the internet to run some of its activities. 


\section{Login Page:}

\section{MODULE DESIGN}

It is the login page, when we first use the app we will get this page. After logging in once then automatically the page will be loaded there after.

\section{Front Page:}

front page consists of link such as students, faculty, parents, placements, pics, alumni, map and notifications. Eah link has its own details present which is explained below.

\section{Students:}

Consists details of the registered student. Details consists of address phone no etc, and also internal marks and external marks of each semester.

\section{Faculty:}

Consists details of faculty, which consists their degree, experience, academic details.

\section{Alumni:}

Consists details of pass out students. . Details consists of address phone no etc, and also internal marks and external marks of each semester.

$\underline{\text { Pics: }}$

This link consists of the pics of students during annual meet, workshop, talks etc.

\section{Map:}

This link consists of college map which gives us a complete picture of the college eg, department, lab etc.

Notifications:

Everyday notifications will be sent at the particular time of the day. All the notifications and other important details will be updated in this link.

\section{Placement:}

Consists details of upcoming companies if the user is eligible to attend the company.

\section{CONCLUSION}

Our project as mentioned above aims at the development of android app which reduces the man power and helps in circulating information about department among the students. It is student friendly application.

\section{REFERENCES}

[1]. Aryans android app is an online application developed by 4 girls of Aryans College of Engineering. Notices intended for students belonging to the college will be uploaded in student's login .This has eliminated the need of notice board in the college. All the official notices will be uploaded in the staff login.

[2]. Zirra E et al proposed an online application for the Training and placement department. This System meant to give more easiness to the users that they can add and retrieve information so quickly.

[3]. I-Notice Board Amroli College an online application which gives instant notification, easy to download syllabus, notice .It also contains Suggestion box and complain box

[4]. Biennial National Conference on Nascent Technologies et al proposed the application where student can get the information such as displaying notices, results, attendance timetables, etc. With the help of this application, not only students can access the information from a remote place but also can avoid the inconvenience of travelling all the way to the institute. 